\title{
Excess body fat in obese and normal-weight subjects
}

\author{
E. Louise Thomas $^{1 *}$, Gary Frost ${ }^{2}$, Simon D. Taylor-Robinson ${ }^{3}$ and Jimmy D. Bell ${ }^{1}$ \\ ${ }^{1}$ Metabolic and Molecular Imaging Group, MRC Clinical Sciences Centre, Imperial College London, Hammersmith Hospital, \\ London W12 ONN, UK \\ ${ }^{2}$ Nutrition and Dietetic Research Group, Department of Investigative Medicine, Imperial College London, Hammersmith \\ Hospital, London W12 ONN, UK \\ ${ }^{3}$ Division of Diabetes, Endocrinology and Metabolism, Department of Medicine, Imperial College London, London, UK
}

\begin{abstract}
Excess body adiposity, especially abdominal obesity and ectopic fat accumulation, are key risk factors in the development of a number of chronic diseases. The advent of in vivo imaging methodologies that allow direct assessment of total body fat and its distribution have been pivotal in this process. They have helped to identify a number of sub-phenotypes in the general population whose metabolic risk factors are not commensurate with their BMI. At least two such sub-phenotypes have been identified: subjects with normal BMI, but excess intraabdominal (visceral) fat (with or without increased ectopic fat) and subjects with elevated BMI ( $>25 \mathrm{~kg} / \mathrm{m}^{2}$ ) but low visceral and ectopic fat. The former sub-phenotype is associated with adverse metabolic profiles, while the latter is associated with a metabolically normal phenotype, despite a high BMI. Here, examples of these phenotypes are presented and the value of carrying out enhanced phenotypical characterisation of subjects in interventional studies discussed.
\end{abstract}

Key words: Adiposity: Obesity: Body fat distribution: Metabolic phenotypes

\section{Introduction}

Obesity has become one of the major health issues of the 21st century, affecting both developed and developing nations. It is estimated that 1.5 billion of the global population will be overweight or obese by the year 2030. The incidence of obesity in the UK alone continues to increase at an alarming rate $^{(1,2)}$. In the UK, $42 \cdot 3 \%$ of men and $32.3 \%$ of women are classified as overweight, with a further $23.3 \%$ of men and $24.4 \%$ of women classified as obese $^{(2)}$. Incidence of obesity in some ethnic groups in the UK is even higher, particularly among females of black Caribbean and black African ethnicities, compared with the general population ${ }^{(2)}$. Levels of obesity in UK children remain high, with $23 \cdot 1 \%$ of 4 - to 5 -year-old children being classified as overweight or obese and $33.3 \%$ of 10- to 11-year-olds classified as overweight or obese $\mathrm{o}^{(2)}$.

It is now generally accepted that elevated levels of body adiposity, especially 'visceral' (intra-abdominal adipose tissue) and hepatic fat, amplify the risks of developing chronic, life-threatening diseases. However, in recent years there have been a number of studies reporting subjects with metabolic profiles that do not always conform to that expected from their BMI. The underlying mechanism that allows this apparent disassociation is not fully understood; however, advances in in vivo imaging techniques, in combination with genetic models, are making significant inroads into this phenomenon. In this review, the evidence relating to the existence of individuals with normal metabolic profiles but elevated BMI ( $>30 \mathrm{~kg} /$ $\mathrm{m}^{2}$ ) and subjects with an abnormal metabolic profile and normal BMI $\left(<25 \mathrm{~kg} / \mathrm{m}^{2}\right)$ are presented and discussed. The existence of these sub-phenotypes is making the scientific community reassess its understanding of the effects of body adiposity on health and disease.

\section{Current status of knowledge}

\section{$B M I$ and adiposity}

There are many methods for estimating relative body adiposity, of which BMI (weight divided by height squared) is the most widely used. Most individuals in the UK attending a doctor's surgery or gym will undergo assessment of body composition by BMI for convenience and ease of interpretation. This is despite the fact that a substantial number of scientific publications have shown the limitations of this technique, particularly in different ethnic

Abbreviations: MHO, metabolically healthy obese; MRS, magnetic resonance spectroscopy; TOFI, thin-on-the-outside fat-on-the-inside.

*Corresponding author: Dr E. Louise Thomas, fax + 44208383 3038, email louise.thomas@csc.mrc.ac.uk 
groups and athletes ${ }^{(3,4)}$. Indeed, in athletes BMI may simply reflect increased muscle mass, which does not infer less favourable health ${ }^{(5)}$. Similarly, a BMI of $20-25 \mathrm{~kg} / \mathrm{m}^{2}$, which would be considered lean and by inference 'healthy' within a Caucasian population, corresponds to an elevated body fat content in other ethnic groups $^{(4)}$, which may therefore underestimate an individual's risk of metabolic disease.

On a 'population level', a strong positive correlation between BMI and overall body fat content has been extensively reported ${ }^{(6)}$. However, this can mask significant variations in the relationship between BMI and body fat distribution on an individual level. For instance, there is a strong correlation between adiposity and BMI for both sexes (males: $r$ 0.64, $P<0.0001$; females: $r$ 0.82, $P<0.0001$ ), with the latter showing a significantly higher percentage body fat at almost every BMI point ${ }^{(7)}$. However, significant variations between individuals within a given BMI can be observed. For instance, at a given BMI (for example, $24 \mathrm{~kg} / \mathrm{m}^{2}$ ), the body fat content as measured by MRI in male and female subjects varies from $7 \cdot 8$ to $38.3 \%$ and from 29.9 to $44.2 \%$, respectively ${ }^{(7)}$. This is further illustrated in Fig. 1, which shows the variation in adipose tissue distribution in transverse abdominal images of nine male subjects all having a BMI of $24 \mathrm{~kg} / \mathrm{m}^{2}$. These images show that there is considerable inter-individual variation in the relative amount of abdominal subcutaneous and visceral fat present in subjects with an identical body fat content; indeed, the levels of visceral fat can vary by up to $400 \%{ }^{(7)}$. Despite evidence that BMI is of limited value in estimating the true body adiposity of an individual, it remains the method of choice in large population studies, particularly in genome-wide-association research programmes seeking to identify the genetic determinants of obesity ${ }^{(8,9)}$.

\section{Waist circumference}

Whilst BMI is often used in research studies as an index of overall obesity, waist circumference is commonly used as a proxy of abdominal obesity ${ }^{(10-12)}$. Several studies have shown waist circumference to be associated with cardiometabolic disease and that it can be used to predict risk of type 2 diabetes ${ }^{(13,14)}$. However, the levels of adipose

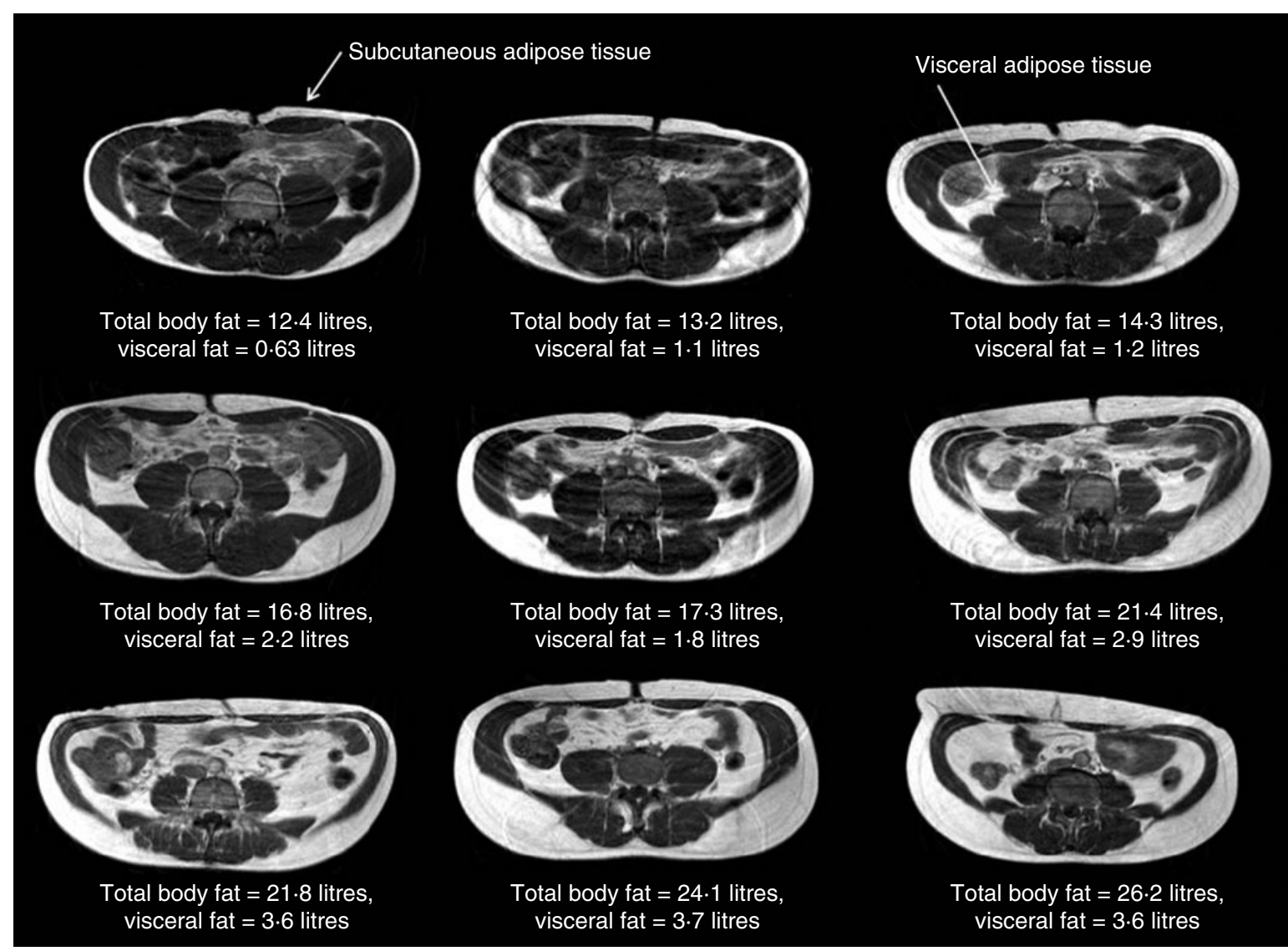

Fig. 1. BMI is poorly predictive of adipose tissue content. In this figure nine transverse abdominal magnetic resonance images showing the distribution of abdominal fat are shown. Subcutaneous and visceral (intra-abdominal) adipose tissues (labelled) appear as bright signals as these are $\mathrm{T}_{1}$-weighted images. Elevated visceral fat is associated with an increased risk of metabolic disease. Subcutaneous fat is generally thought to carry less risk. Each image was taken at the level of the umbilicus from nine different Caucasian male subjects, all with an identical BMI (in this example $24 \mathrm{~kg} / \mathrm{m}^{2}$ ). Despite these subjects having the same BMI, the distribution and amount of total and regional adipose tissue vary greatly (total body fat content range 12.4-26.2 litres, visceral fat content range $0.63-3 \cdot 7$ litres). These examples clearly show that BMI is not a good predictor of an individual's fat content. 
tissue, both subcutaneous and visceral, vary significantly for a single given waist circumference ${ }^{(7)}$. Fig. 2 shows how individuals with an identical waist circumference exhibit a considerable intra-individual variation in fat content and distribution. Direct measurement of individual fat depots appears to be imperative to unravel the relationship between body fat and metabolic dysregulation.

\section{Enhanced adiposity phenotyping}

Indirect methods of body composition analysis, such as BMI, anthropometry, bioimpedance and plethysmography are not always suitable for detailed studies of body composition, since they cannot determine visceral adipose tissue distribution $^{(3,15-21)}$. Similarly, dual-energy X-ray absorptiometry, which is now commonly used to measure total and abdominal fat content, cannot be used to assess ectopic fat. Ectopic fat refers to fat deposited outside the classical adipose tissue depots into organs such as the liver, muscle and pancreas. Its presence in these organs conveys specific metabolic risk. As such, the ability to measure ectopic fat is a key factor in choosing suitable methodology for enhanced phenotyping. The inability of standard techniques to measure both adipose tissue and ectopic fat depots in detail has greatly hampered our ability to fully discern the cause-effect relationship between body adiposity and an individual's metabolic and cardiovascular risk factors. Indeed, using conventional methods of measuring body composition, individuals with a wide range of visceral and ectopic fat content can be categorised as having identical body adiposity.

The desire to accurately phenotype individuals has been one of the driving forces behind the development of direct, non-invasive methods, such as MRI and magnetic resonance spectroscopy (MRS), to measure total and regional adipose content ${ }^{(18,22-39)}$. The most commonly used MRI method in body composition tends to be $\mathrm{T}_{1}$-weighted imaging (conventional MRI images in which the fat appears bright and other tissues grey; examples of these images are shown in Fig. 1), especially for whole-body fat measurements. These are routine techniques that can be applied on both clinical and research MRI scanners, enabling widespread application. More recently multiecho imaging and chemical shift-based techniques have also been developed to quantify fat deposition in the abdomen, liver and pancreas. These methods manipulate the frequency difference between water and fat signals to generate multiple images from which tissue fat content

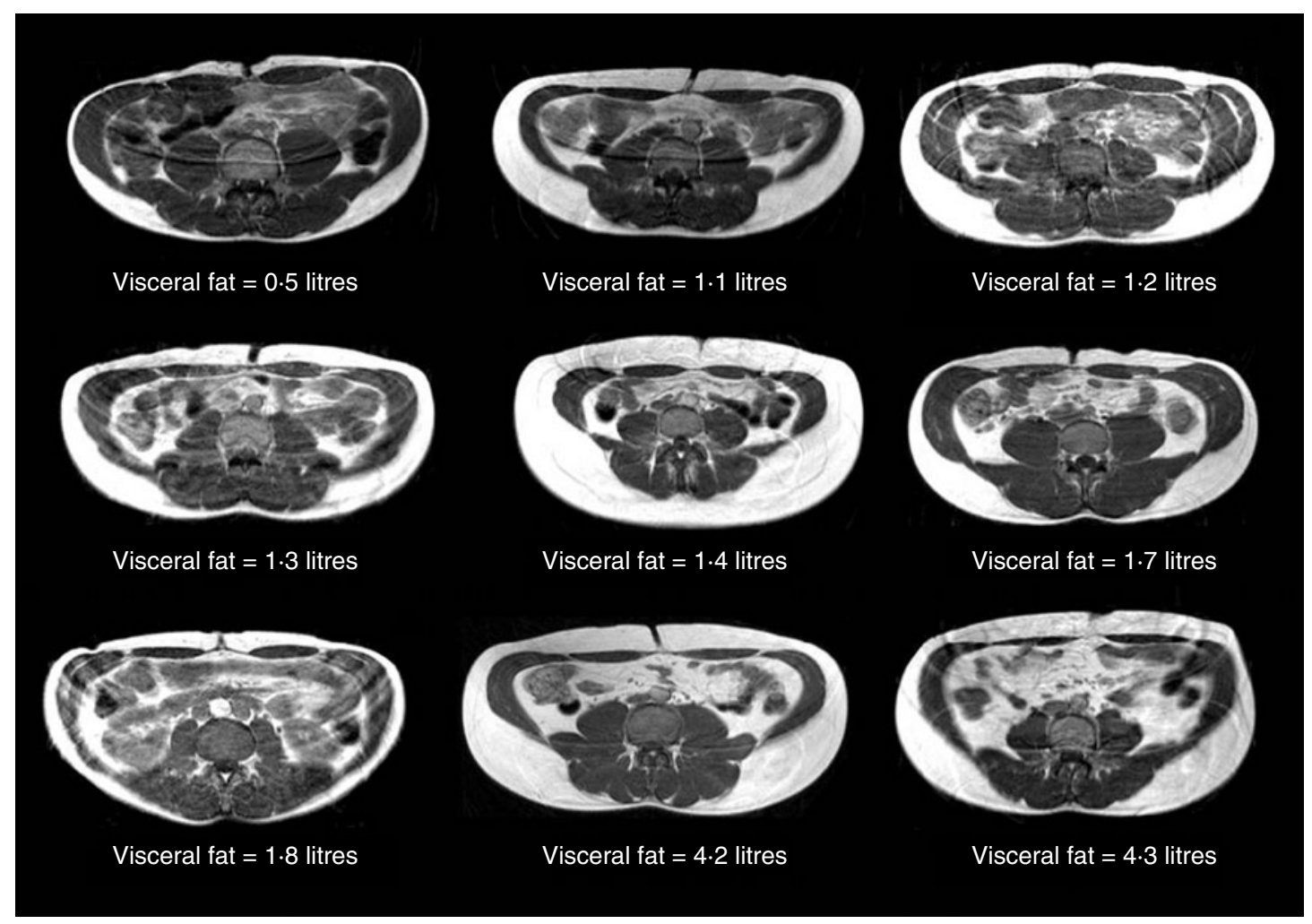

Fig. 2. Waist circumference is a poor predictor of an individual's visceral fat content. In this figure nine transverse magnetic resonance images taken at the level of the umbilicus from nine different Caucasian male subjects each with an identical waist circumference of $84 \mathrm{~cm}$ (measured with a tape-measure at the mid-point of the waist) are shown. As can be clearly seen in the figure, there are very obvious visual differences between the images from different subjects, particularly in regards to the amount of visceral fat that is present. Indeed, the visceral fat content varies from $0.5-4.3$ litres, suggesting that at least on an individual level, waist circumference is a very poor predictor of abdominal and, in particular, visceral fat content. The importance of this cannot be underestimated given that waist circumference is often used as a proxy of abdominal fat content. 
can be measured; these methods tend to be limited to specialist research centres ${ }^{(31-39)}$. For an in-depth review of MRI techniques to measure abdominal adipose tissue and organ fat content, see Hu et al. ${ }^{(39)}$

Proton MRS $\left({ }^{1} \mathrm{H}-\mathrm{MRS}\right)$ to measure ectopic fat content in the muscle ${ }^{(40-44)}$ and liver ${ }^{(45-49)}$ has been extensively validated against other techniques, including biopsy ${ }^{(50)}$. More recently MRS has been used to assess fat content in organs such as the pancreas ${ }^{(35,51)}$ and heart ${ }^{(52)}$. Measurement of fat in the pancreas and heart is more technically demanding than in the liver and muscle, partly related to the size, position and motion associated with these organs; as yet these measurements have not been fully validated. While ${ }^{1} \mathrm{H}$-MRS is considered the 'gold standard' to measure fat in the liver and muscle, further work is required before it can be regarded as such in the pancreas or heart.

Magnetic resonance-based techniques have become the methods of choice for enhanced adiposity phenotyping; in a single MRI examination total and regional adipose tissue content, in addition to muscle, liver and pancreatic fat content can be obtained (Fig. 3).

\section{Body composition by whole-body MRI and magnetic resonance spectroscopy}

Visceral fat and ectopic fat within the liver have been shown to be stronger and independent predictors of markers of the metabolic syndrome ${ }^{(53-55)}$ than subcutaneous fat depots. Indeed, subcutaneous adiposity appears to be relatively protective rather than harmful ${ }^{(19,56)}$ and is the strongest predictor of plasma levels of leptin, the fatderived hormone that reduces appetite ${ }^{(57-59)}$. Conversely, ectopic muscle fat correlates with markers of insulin resistance and visceral adiposity ${ }^{(60-62)}$, while liver fat content correlates with total and visceral adiposity, and liver enzyme abnormalities ${ }^{(45)}$

The identification of visceral fat and liver fat as fundamental contributors to the development of co-morbidities of obesity has led to a dynamic search for effective lifestyle and pharmacological/clinical interventions to contain or reduce their impact on health. Cross-sectional and interventional studies using imaging techniques have revealed a number of factors that make an impact on the amount, and crucially the distribution and composition, of fat deposited

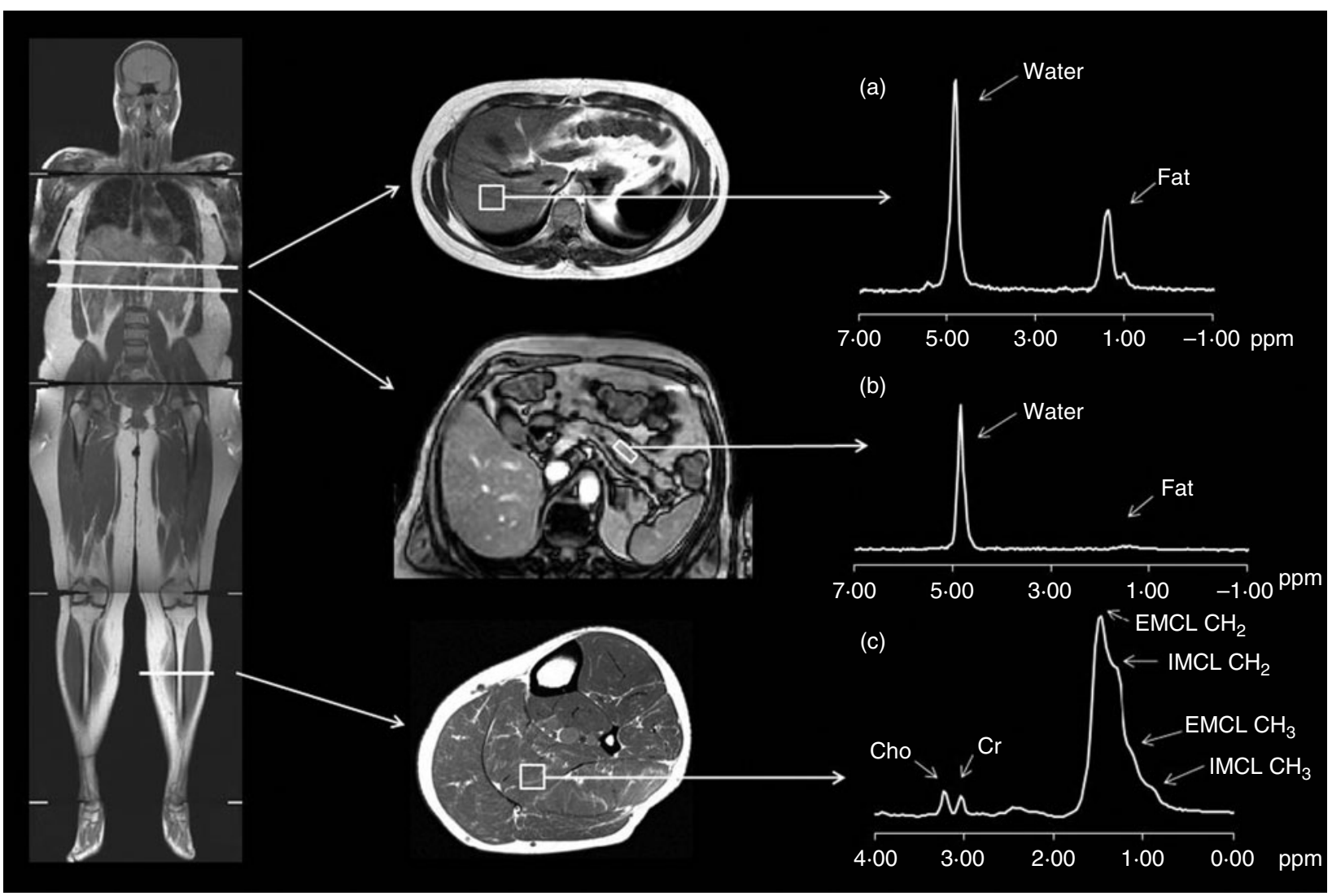

Fig. 3. Measurement of fat content by ${ }^{1} \mathrm{H}$-magnetic resonance spectroscopy. Transverse magnetic resonance images were taken through the abdomen to identify the liver and pancreas, and the lower leg to identify soleus and tibialis muscles. Voxels were placed in the organ of interest avoiding bone, blood vessels and obvious fatty streaks. ${ }^{1} \mathrm{H}$-magnetic resonance spectra were obtained in approximately 2 min from (a) the liver, (b) pancreas and (c) soleus muscle. The ectopic fat content of the liver and pancreas was determined by measuring the ratio of the fat peak (specifically the $\mathrm{CH}_{2}$ resonance) to the water peak. The ectopic fat content in the muscle (or intramyocellular lipid; IMCL) was measured from the ratio of the fat (again the $\mathrm{CH}_{2}$ resonance), which arises from lipids within the myocyte, this time measured relative to total muscle creatine $(\mathrm{Cr})$ content. These ratios were all corrected for $\mathrm{T}_{1}$ and $\mathrm{T}_{2}$ relaxation effects (these are NMR effects which are related to how long it takes for the NMR signal to relax back to equilibrium; correcting for them allows spectra to be obtained faster). ppm, Parts per million; EMCL, extramyocellular lipid; Cho, choline. 
within the body. Whilst an in-depth review of this area of research is beyond the scope of the present paper, these phenotyping methods have enabled the study of the influences of: (i) diet on adipose tissue fatty acid composition $^{(63,64)}$; (ii) ethnicity on ectopic fat and abdominal obesity ${ }^{(60,65-67)}$; (iii) the environment in the womb, with preserved visceral fat in infants with growth retardation and fat changes during catch-up growth after birth $^{(68,69)}$; and (iv) sex differences on abdominal fat reduction with weight loss ${ }^{(70)}$. Furthermore, an increasing number of studies have shown associations of variants in various genes (for example, angiotensin-converting enzyme $(A C E)$, adiponectin $(A D I P O Q), \beta-2$ adrenergic receptor $(A D R B 2)$, apoA2 ( $A P O A 2)$, fatty acid-binding protein-2 (FABP2), lymphotoxin- $\alpha$ (LTA), microsomal triglyceride transfer protein $(M T T P)$, perilipin $(P L I N)$, PPAR $\gamma(P P A R G)$ and uncoupling protein-1 (UCP1)) with measures of body fat distribution, including visceral and abdominal subcutaneous fat, waist:hip ratio, waist circumference and sagittal diameter ${ }^{(71)}$.

More recently, genome-wide-association study analysis has identify an insulin receptor substrate-1 (IRS1)-associated allele with reduced subcutaneous adipose tissue but paradoxically increased metabolic risk $^{(72)}$, confirming the importance of accurate in-depth phenotypic characterisation in scientific research. Indeed, most genome-wideassociation studies and SNP-environment interactions for obesity and diabetes studies have utilised the muchquestioned BMI or waist:hip ratio as a measure of obesity and/or body adiposity ${ }^{(73-75)}$. Similarly, studies on hepatic steatosis heritability have been carried out using computerised tomography $(\mathrm{CT})$ in relatively small populations ${ }^{(76)}$. This has greatly limited the relative health impact of such studies.

\section{Metabolically normal obesity}

Excess body fat does not always appear to be associated with metabolically adverse profiles such as increased risk of insulin resistance, glucose intolerance, type 2 diabetes and $\mathrm{CVD}^{(77-79)}$. There is a growing body of evidence that supports the existence of 'metabolically normal obesity'. These subjects have been referred to as metabolically healthy obese $(\mathrm{MHO})^{(80-84)}$ and can carry considerable levels of body fat, but maintain normal insulin sensitivity and blood pressure, high HDL and low plasma TAG levels ${ }^{(81,84-86)}$. The incidence of $\mathrm{MHO}$ varies between studies, partly due to the manner in which MHO is defined. In Germany, Stefan et al. ${ }^{(80)}$ reported $24.4 \%$ of their obese population as $\mathrm{MHO}$, on the basis of their insulin sensitivity, whilst in an Italian study by Bonora et al. ${ }^{(86)}$ approximately $20 \%$ of their obese individuals fit the MHO profile. Similarly Wildman et $a l .^{(81)}$ in the USA reported an incidence of $\mathrm{MHO}$ in 35.4 and $29.2 \%$ of obese women and men, respectively. MHO was defined as having only one of six common cardiometabolic risk factors (elevated blood pressure, elevated TAG, C-reactive protein, insulin resistance, elevated glucose levels/diabetes, or decreased HDL $)^{(81,84,87)}$.

A related phenotype includes obese subjects who are defined as "fat-fit'(82,88-90). At present it is unclear how much overlap there is between the MHO and fit-fat phenotypes. Interestingly, there is a growing body of evidence that fat but fit individuals have substantially lower mortality risk than normal-weight unfit individuals ${ }^{(82,89,90)}$. This apparent dissociation between body fat content and adverse metabolic profile may be in part related to body fat distribution, since different adipose tissue depots are known to carry proportionally different risk in terms of $\mathrm{CVD}^{(91)}$.

A key contributory factor to this dissociation must therefore be a severance between visceral/liver fat and total body adiposity. This sub-phenotype has been clearly identified by our group and others, where subjects with elevated BMI show normal levels of visceral and ectopic fat depots (i.e. reduced compared with the general obese population) and healthy metabolic profiles ${ }^{(80,90,92)}$. In many ways this is similar to the phenotype observed in Japanese Sumo wrestlers, who have reduced visceral adiposity accompanied by high insulin sensitivity despite their elevated total fat content ${ }^{(93,94)}$. The underlying mechanisms leading to the development of this sub-phenotype are not known, but factors such as increased physical activity may be important. Lee et al. ${ }^{(95)}$ have shown that physical fitness reduces or eliminates the risks associated with obesity, while O'Donovan et al. ${ }^{(90)}$ have reported that subjects with improved $\mathrm{VO}_{2 \max }$ show a significant reduction in abdominal obesity despite their elevated BMI.

\section{Excess body fat in normal-weight subjects}

In addition to 'metabolically normal obesity', the opposite phenotype, comprising of lean subjects (BMI $<25 \mathrm{~kg} / \mathrm{m}^{2}$ ) with the metabolic phenotype of an obese individual, has been reported and poses a potentially serious hidden risk for a significant proportion of the population. These individuals have been referred to as 'metabolically obese but normal-weight' (MONW) ${ }^{(96)}$. These subjects have been shown to have reduced insulin sensitivity, increased abdominal adiposity, a more atherogenic lipid profile, and raised blood pressure, accompanied by physical inactivity and a low $\mathrm{VO}_{2 \max }$. The combination of these factors is thought to predispose 'metabolically obese but normal-weight' subjects to an increased risk of type 2 diabetes and CVD $^{(84,97-103)}$

This phenotype has been further refined using MRI to show disproportionate deposition of visceral adipose tissue, with many lean subjects having more visceral adipose tissue than overweight or obese subjects (Fig. 4). This TOFI (thin-on-the-outside fat-on-the-inside) subphenotype has been observed in both male and female subjects, and increases an individual's risk of metabolic 

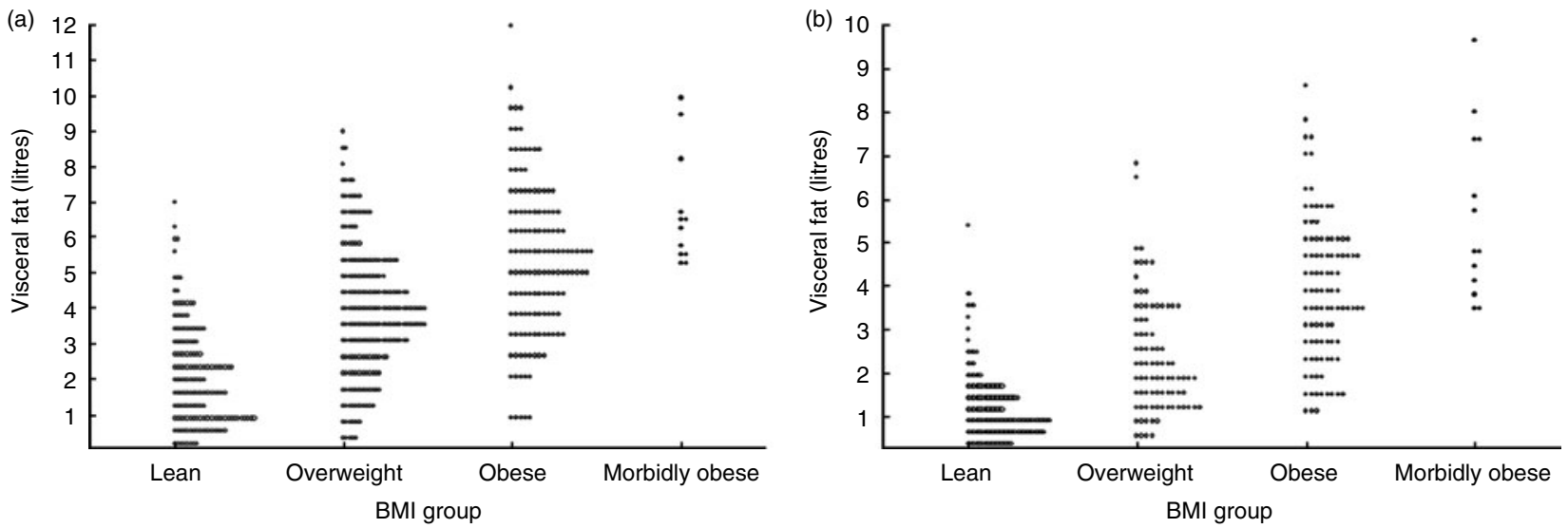

Fig. 4. Overlap in visceral fat content between male (a) and female (b) lean and obese individuals. Absolute levels of visceral fat in lean (BMI $20-25 \mathrm{~kg} / \mathrm{m}^{2}$; 156 male, 182 female), overweight (BMl $25-30 \mathrm{~kg} / \mathrm{m}^{2} ; 213$ male, eighty-six female), obese BMl $\left(30-40 \mathrm{~kg} / \mathrm{m}^{2} ; 140\right.$ male, 982 female) and morbidly obese (BMI $>40 \mathrm{~kg} / \mathrm{m}^{2}$; twelve male, thirteen female) subjects. Note the overlap between visceral fat levels between the different BMI groups. Many lean individuals have as much or more visceral fat than overweight, obese and, in some instances, morbidly obese subjects.

disease $^{(7)}$. An example of this can be seen in Fig. 5. The elevated visceral fat found in individuals classified as TOFI (higher ratio of visceral:subcutaneous abdominal adipose tissue) was accompanied by increased levels of both liver and muscle fat. Identifying subjects classified as TOFI may be important, since they may be at increased risk of metabolic disease compared with more obese subjects with less visceral fat. Incidence of 'metabolically-obese but normal-weight' has been reported to be between 13 and $18 \%^{(84,102)}$, which is similar to the incidence of TOFI $(12 \% \text { women, } 14 \% \text { men })^{(7)}$. Interestingly, a similar finding has been reported in obese individuals, where obese subjects with a disproportionate accumulation of visceral fat had increased incidence of disorders of glucose and lipid metabolism ${ }^{(104)}$

Again, as with the MHO and 'fat-fit' individuals, the underlying mechanisms behind the accumulation of disproportionate levels of visceral and liver fat in subjects with a normal body weight are not fully understood. Potential causes include physical inactivity, ageing, sex hormones, dietary composition and genetic factors ${ }^{(103)}$; further research is needed to explain the exact mechanisms responsible for this phenotype. Després \& Lemieux ${ }^{(105)}$ proposed that excess visceral fat deposition could be a marker of 'dysfunctional' adipose tissue, which in turn is associated with increased ectopic fat deposition in the liver, heart, skeletal muscle and pancreas.

\section{Obesity in lean tissue - the problem of ectopic fat}

It has been recently suggested that in the development of insulin resistance and type 2 diabetes, accumulation of lipids outside the classical adipose tissue depots may be the critical factor ${ }^{(106)}$. Lipid accumulation in non-adipose cells (ectopic fat) may impair the normal housekeeping function of some tissues through a process known as lipotoxicity $^{(107)}$. Ectopic storage of excess lipids in 'lean body mass', via organs such as the liver, skeletal muscle and $\beta$-cells of the pancreas has therefore been proposed as the causative link between fat distribution and the metabolic syndrome ${ }^{(108)}$. Ectopic fat deposition has also been shown to affect both renal and cardiovascular function and may contribute to the development of $\mathrm{CVD}^{(109)}$. For example, subjects with lipodystrophy have disproportionally

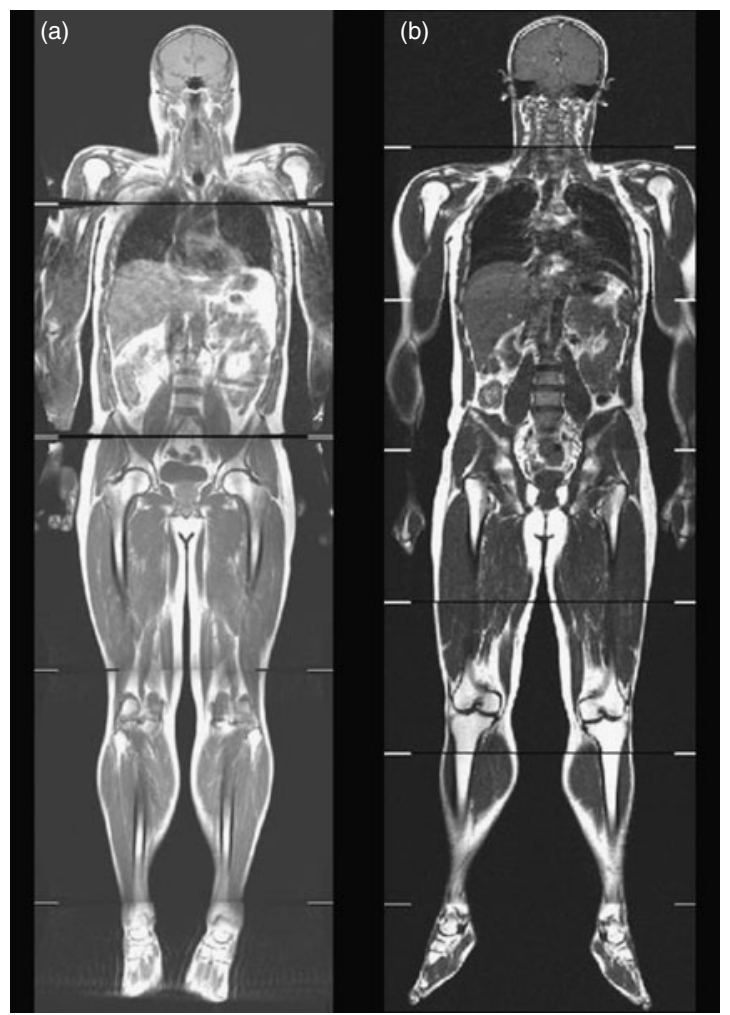

Fig. 5. Whole-body coronal images demonstrating the TOFI (thin-outside fatinside) phenomenon. The male individuals shown in this figure are of similar age, $\mathrm{BMI}$ and percentage body fat but have different levels of visceral fat and therefore different disease risks. Subject (a) is a TOFI (BMI $25.8 \mathrm{~kg} / \mathrm{m}^{2}$; 3.3 litres of visceral fat); subjects (b) is a healthy volunteer (BMI $26.5 \mathrm{~kg} / \mathrm{m}^{2}$; $2 \cdot 2$ litres of visceral fat). 

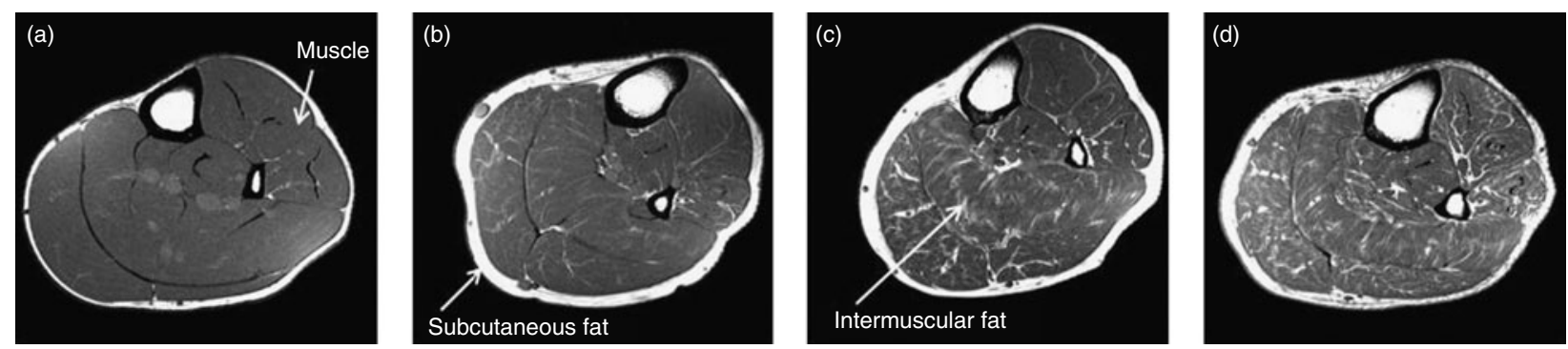

Fig. 6. Intermuscular adipose tissue increases with increasing age and decreasing insulin sensitivity. Transverse magnetic resonance images from the calf muscle from four Caucasian male volunteers: (a) an athlete aged 23 years; (b) a healthy volunteer aged 35 years; (c) a healthy volunteer aged 60 years; (d) a 68 -year-old volunteer with type 2 diabetes. Fat (intermuscular adipose tissue, also referred to as extramyocellular lipid) accumulates between muscle fibres as muscles age and become more insulin resistant.

raised levels of ectopic fat, despite very low levels of adipose tissue ${ }^{(110,111)}$.

Early studies showed that TAG are elevated within muscle cells of rodent models of diabetes and in human diabetic patients ${ }^{(112-114)}$, and this elevation was inversely related to insulin action ${ }^{(115-118)}$. Accumulation of liver fat (steatosis) in relation to diabetes was reported incidentally as early as $1884^{(119)}$, although, until recently, fat accumulation in the liver was assumed to be a relatively benign condition. However, reports showing increased incidence of cirrhosis in obese and type 2 diabetic subjects have challenged this view ${ }^{(120-123)}$. Recent studies have shown that
$25-50 \%$ of patients with steatosis subsequently became diabetic, suggesting that hepatic steatosis may have a direct causative effect in the development of diabetes $^{(124,125)}$. Similarly, this has also been linked to the development of $\mathrm{CVD}^{(125)}$, suggesting that non-alcoholic fatty liver disease is an independent risk factor for metabolic disease. Furthermore, an abundance of fat within the liver can also progress to steatohepatitis, cirrhosis and potentially hepatocellular carcinoma ${ }^{(126)}$. Non-alcoholic fatty liver disease is increasing in incidence and is a common finding in the general population; it is becoming the most prevalent cause of chronic liver disease

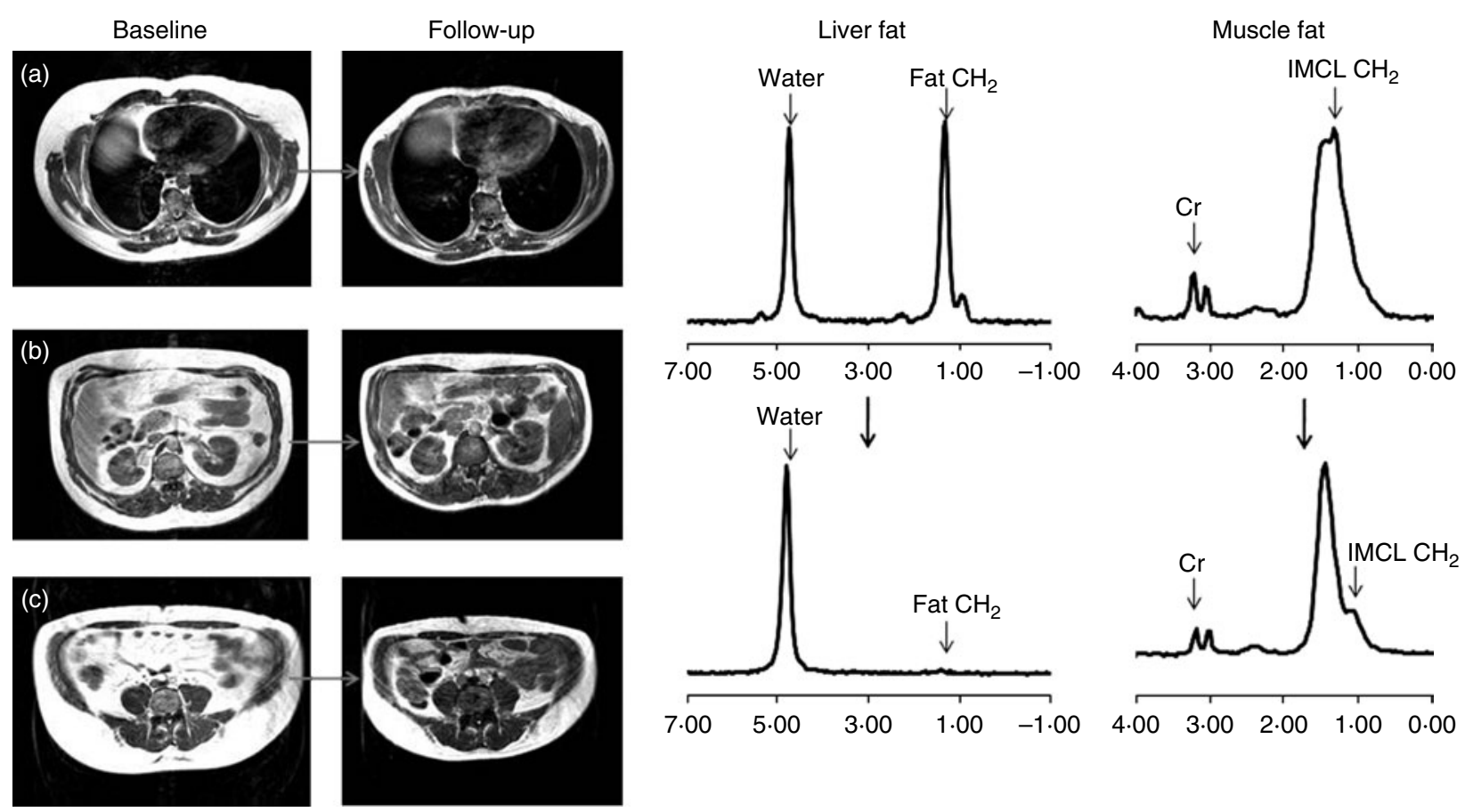

Fig. 7. Effect of 6 months' life-style intervention on adipose tissue and ectopic fat content. Life-style intervention over a 6-month period involving reducing portion size and increasing physical activity can have a dramatic effect on body fat content. This individual lost $33 \mathrm{~kg}$ of body fat. Three sample images from a total dataset of 113 slices are shown. These three images all show visual reductions in subcutaneous fat; they also show clear reductions in internal fat deposits from around organs including the heart (a), kidneys (b) and from intra-abdominal adipose tissue depots (c). These changes were accompanied by significant reductions in ectopic fat in both liver and muscle as can be seen in the spectra from the liver and muscle. Liver fat was reduced from 38 to $0.6 \%$ (calculated as the ratio of $\mathrm{CH}_{2}$ of fat peak to water peak, corrected for $\mathrm{T}_{1}$ and $\mathrm{T}_{2}$ relaxation effects) and muscle fat was reduced from 18 to $6 \%$ (calculated as the ratio of $\mathrm{CH}_{2}$ of fat peak to creatine ( $\mathrm{Cr}$ ) peak, corrected for $\mathrm{T}_{1}$ and $\mathrm{T}_{2}$ relaxation effects). Overall, this figure illustrates the benefit of enhanced phenotyping, from one examination combining MRI and magnetic resonance spectroscopy; reductions in adipose tissue and ectopic fat in response to life-style modification can be observed and quantified from several metabolically important sites. IMCL, intramyocellular lipid. 
worldwide. The prevalence of non-alcoholic fatty liver disease in Western countries is estimated to range from 6 to $30 \%$, and has been reported to be present in as many as $63-98 \%$ of the obese and morbidly obese populations (Vernon et al. ${ }^{(127)}$ and references within).

There are a number of hypotheses as to the potential mechanism behind the increased accretion of ectopic fat $^{(128,129)}$. These include increased uptake, decreased oxidation/disposal and increased de novo synthesis of TAG in the liver, as well as the so-called 'overflow hypothesis' where adipose tissue is unable to expand to uptake/ retain excess fat from the circulation, necessitating accumulation of fat in non-adipocyte cells. Much of the current research appears to support the notion that each of these mechanisms, to varying extent, is implicated in accretion of ectopic fat in disease.

Until recently ectopic fat was assessed by the use of needle biopsy in combination with electron microscopy/ oil staining. This had limited application in tissues such as the heart and pancreas, besides the issues for longitudinal studies in heterogeneous tissues, such as the liver. Noninvasive methods available include ultrasound, which tends to be regarded as an initial screening tool for hepatic steatosis due to being non-invasive, inexpensive, and widely available. However, poor sensitivity and specificity of ultrasound, particularly for mild to moderate $(<20 \%)$ levels of fat infiltration, have led many to question whether it is an appropriate screening tool for fatty liver disease ${ }^{(130)}$. Today, the advent of computerised tomography (CT), MRI and MRS has revolutionised the study of ectopic fat, allowing fast and reproducible non-invasive quantitative measurement of lipids in the muscle, liver and pancreas (Fig. 3). Increased availability and access to magnetic resonance scanners have made it a more viable alternative as a clinical screening tool, rather than a pure research measurement.

The measurement of ectopic fat, particularly in the liver, has become an important issue in light of recent publications which have suggested that excess hepatic fat is more physiologically relevant than visceral fat in the development of the metabolic syndrome. Indeed, the phenotype of metabolically healthy obese individuals, as mentioned previously, has reduced fat in the liver ${ }^{(80,90)}$. Fabbrini et al. ${ }^{(54)}$ have suggested that increased liver fat is an independent indicator of multi-organ insulin resistance and postulate that the observed relationship between increased visceral fat and metabolic disease is essentially a confounding factor due to the correlation between visceral and liver fat. More recently, Magkos et al. ${ }^{(131)}$ have shown that increased adiposity, without an increase in liver fat, does not cause abnormalities in adipose tissue, skeletal muscle and hepatic insulin sensitivity, and VLDL metabolism.

In addition to the accumulation of fat within muscle cells (intramyocellular lipid), several studies recently measured intermuscular adipose tissue using MRI, which is adipose tissue located between muscle bundles ${ }^{(132)}$, akin to the marbling found in steak (Fig. 6). Expansion of this depot has been shown to be related to insulin resistance ${ }^{(133)}$.

\section{Life-style changes and body adiposity}

A full understanding of the long-term health implications of abdominal obesity and associated metabolic, inflammatory and endocrine markers should drive innovative translational approaches directed towards better maintenance of health and quality of life. In small-scale interventional studies, health benefits have been observed with: (i) moderate exercise and dietary changes to alter muscle fat and liver fat, and reduce visceral fat as shown in Fig. 7 ${ }^{(134-138)}$; (ii) moderate energy restriction to reduce liver and visceral fat and improve insulin sensitivity ${ }^{(139-142)}$; (iii) influence of sex and ethnicity on life-style intervention $^{(70,143,144)}$; (iv) exercise training to alter muscle and fat volume that differs with a genetic variant indicating gene-environment interactions ${ }^{(145-147)}$; and (v) twin discordance on physical activity and body composition $^{(148,149)}$. Many of these findings are beginning to find their way into the life-style choices of individuals, thus improving the health of the population as a whole.

In conclusion, despite the well-known association between increased body fat content and increased adverse metabolic risk factors, the advent of non-invasive imaging techniques has allowed identification of a number of sub-phenotypes that point to the importance of fat distribution, as well as total fat content, in the development of chronic metabolic disorders.

\section{Acknowledgements}

The authors would like to acknowledge the contribution of Anthony Goldstone, Julie Fitzpatrick, Giuliana Durighel and Paul Baruya. The authors would like to acknowledge funding from the UK MRC (Medical Research Council) and NIHR (National Institute for Health Research) Biomedical Research Centre. All authors were involved in the design and writing of this paper. All authors gave final approval of the text. None of the authors has any conflict of interest to declare.

\section{References}

1. Devaux M \& Sassi F (2011) Social inequalities in obesity and overweight in 11 OECD countries. Eur J Public Health (epublication ahead of print version 6 June 2011).

2. National Obesity Observatory (2010) Statistics from Health Survey for England. http://www.noo.org.uk/news.php

3. Prentice AM \& Jebb SA (2001) Beyond body mass index. Obes Rev 2, 141-147.

4. Deurenberg P \& Deurenberg-Yap M (2003) Validity of body composition methods across ethnic population groups. Forum Nutr 56, 299-301.

5. Kragelund C \& Omland T (2005) A farewell to body-mass index? Lancet 366, 1589-1591. 
6. Okorodudu DO, Jumean MF, Montori VM, et al. (2010) Diagnostic performance of body mass index to identify obesity as defined by body adiposity: a systematic review and meta-analysis. Int J Obes 34, 791-799.

7. Thomas EL, Parkinson JR, Frost GS, et al. (2012) The missing risk: MRI and MRS phenotyping of abdominal adiposity and ectopic fat. Obesity 20, 76-87.

8. Zhao J, Bradfield JP, Zhang H, et al. (2011) Role of BMIassociated loci identified in GWAS meta-analyses in the context of common childhood obesity in European Americans. Obesity 19, 2436-2439.

9. Walters RG, Jacquemont S, Valsesia A, et al. (2010) A new highly penetrant form of obesity due to deletions on chromosome 16p11.2. Nature 463, 671-675.

10. Klein S, Allison DB, Heymsfield SB, et al. (2007) Waist circumference and cardiometabolic risk: a consensus statement from shaping America's health: Association for Weight Management and Obesity Prevention; NAASO, the Obesity Society; the American Society for Nutrition; and the American Diabetes Association. Diabetes Care 30, $1647-1652$.

11. Pouliot MC, Després JP, Lemieux S, et al. (1994) Waist circumference and abdominal sagittal diameter: best simple anthropometric indexes of abdominal visceral adipose tissue accumulation and related cardiovascular risk in men and women. Am J Cardiol 73, 460-468.

12. Lean ME, Han TS \& Morrison CE (1995) Waist circumference as a measure for indicating need for weight management. BMJ 311, 158-161.

13. Janssen I, Katzmarzyk PT \& Ross R (2002) Body mass index, waist circumference, and health risk: evidence in support of current National Institutes of Health guidelines. Arch Intern Med 162, 2074-2079.

14. Wang Y, Rimm EB, Stampfer MJ, et al. (2005) Comparison of abdominal adiposity and overall obesity in predicting risk of type 2 diabetes among men. Am J Clin Nutr 81, 555-563.

15. Deurenberg P (1996) Limitations of the bioelectrical impedance method for the assessment of body fat in severe obesity. Am J Clin Nutr 64, Suppl. 3, S449-S452.

16. Bonora E, Micciolo R, Ghiatas AA, et al. (1995) Is it possible to derive a reliable estimate of human visceral and subcutaneous abdominal adipose tissue from simple anthropometric measurements? Metabolism 44, 1617-1625.

17. Tothill P, Han TS, Avenell A, et al. (1996) Comparisons between fat measurements by dual-energy X-ray absorptiometry, underwater weighing and magnetic resonance imaging in healthy women. Eur J Clin Nutr 50, 747-752.

18. Thomas EL, Saeed N, Hajnal JV, et al. (1998) Magnetic resonance imaging of total body fat. J Appl Physiol 85, $1778-1785$.

19. Pou KM, Massaro JM, Hoffmann U, et al. (2009) Patterns of abdominal fat distribution: the Framingham Heart Study. Diabetes Care 32, 481-485.

20. Mehta SR, Thomas EL, Patel N, et al. (2010) Proton magnetic resonance spectroscopy and ultrasound for hepatic fat quantification. Hepatol Res 40, 399-406.

21. Thomas EL, Collins AL, McCarthy J, et al. (2010) Estimation of abdominal fat compartments by bioelectrical impedance the validity of the ViScan measurement system in comparison with MRI. Eur J Clin Nutr 64, 525-533.

22. Fowler PA, Fuller MF, Glasbey CA, et al. (1991) Total and subcutaneous adipose tissue in women: the measurement of distribution and accurate prediction of quantity by using magnetic resonance imaging. Am J Clin Nutr 54, 18-25.

23. Ross R, Léger L, Morris D, et al. (1992) Quantification of adipose tissue by MRI: relationship with anthropometric variables. J Appl Physiol 72, 787-795.
24. Barnard ML, Schwieso JE, Thomas EL, et al. (1996) Development of a rapid and efficient magnetic resonance imaging technique for analysis of body fat distribution. NMR Biomed 9, 156-164.

25. Mitsiopoulos N, Baumgartner RN, Heymsfield SB, et al. (1998) Cadaver validation of skeletal muscle measurement by magnetic resonance imaging and computerized tomography. J Appl Physiol 85, 115-122.

26. Thomas EL \& Bell JD (2003) Influence of undersampling on magnetic resonance imaging measurements of intraabdominal adipose tissue. Int J Obes Relat Metab Disord 27, 211-218.

27. Machann J, Thamer C, Schnoedt B, et al. (2005) Standardized assessment of whole body adipose tissue topography by MRI. J Magn Reson Imaging 21, 455-462.

28. Sohlström A, Wahlund LO \& Forsum E (1993) Adipose tissue distribution as assessed by magnetic resonance imaging and total body fat by magnetic resonance imaging, underwater weighing, and body-water dilution in healthy women. Am J Clin Nutr 58, 830-838.

29. Harrington TA, Thomas EL, Modi N, et al. (2002) Fast and reproducible method for the direct quantitation of adipose tissue in newborn infants. Lipids 37, 95-100.

30. Olhager E, Flinke E, Hannerstad U, et al. (2003) Studies on human body composition during the first 4 months of life using magnetic resonance imaging and isotope dilution. Pediatr Res 54, 906-912.

31. O'Regan DP, Callaghan MF, Wylezinska-Arridge M, et al. (2008) Liver fat content and T2 feasibility. Radiology $\mathbf{2 4 7}$, $550-557$.

32. Springer F, Machann J, Schwenzer NF, et al. (2010) Quantitative assessment of intrahepatic lipids using fat-selective imaging with spectral-spatial excitation and in-/opposedphase gradient echo imaging techniques within a study population of extremely obese patients: feasibility on a short, wide-bore MR scanner. Invest Radiol 45, 484-490.

33. Schwenzer NF, Machann J, Martirosian P, et al. (2008) Quantification of pancreatic lipomatosis and liver steatosis by MRI: comparison of in/opposed-phase and spectralspatial excitation techniques. Invest Radiol 43, 330-337.

34. Borra RJ, Salo S, Dean K, et al. (2009) Nonalcoholic fatty liver disease: rapid evaluation of liver fat content with inphase and out-of-phase MR imaging. Radiology 250, 130-136.

35. Hu HH, Kim HW, Nayak KS, et al. (2010) Comparison of fatwater MRI and single-voxel MRS in the assessment of hepatic and pancreatic fat fractions in humans. Obesity 18, 841-847.

36. Yokoo T, Shiehmorteza M, Hamilton G, et al. (2011) Estimation of hepatic proton-density fat fraction by using MR imaging at 3.0 T. Radiology 258, 749-759.

37. Yokoo T, Bydder M, Hamilton G, et al. (2009) Nonalcoholic fatty liver disease: diagnostic and fat-grading accuracy of low-flip-angle multiecho gradient-recalled-echo MR imaging at 1.5 T. Radiology 25, 67-76.

38. Meisamy S, Hines CD, Hamilton G, et al. (2011) Quantification of hepatic steatosis with T1-independent, T2-corrected MR imaging with spectral modelling of fat: blinded comparison with MR spectroscopy. Radiology 258, 767-775.

39. Hu HH, Nayak KS \& Goran MI (2011) Assessment of abdominal adipose tissue and organ fat content by magnetic resonance imaging. Obes Rev 12, e504-e 515.

40. Schick F, Eismann B, Jung WI, et al. (1993) Comparison of localized proton NMR signals of skeletal muscle and fat tissue in vivo: two lipid compartments in muscle tissue. Magn Reson Med 29, 158-167. 
41. Boesch C, Slotboom J, Hoppeler H, et al. (1997) In vivo determination of intra-myocellular lipids in human muscle by means of localized ${ }^{1} \mathrm{H}-\mathrm{MR}$-spectroscopy. Magn Reson Med 37, 484-493.

42. Rico-Sanz J, Thomas EL, Jenkinson G, et al. (1999) Diversity in levels of intracellular total creatine and triglycerides in human skeletal muscles observed by (1)H-MRS. J Appl Physiol 87, 2068-2072.

43. Szczepaniak LS, Babcock EE, Schick F, et al. (1999) Measurement of intracellular triglyceride stores by ${ }^{1} \mathrm{H}$ spectroscopy: validation in vivo. Am J Physiol 276, E977-E989.

44. Howald H, Boesch C, Kreis R, et al. (2002) Content of intramyocellular lipids derived by electron microscopy, biochemical assays, and (1)H-MR spectroscopy. J Appl Physiol 92, 2264-2272.

45. Thomas EL, Hamilton G, Patel N, et al. (2005) Hepatic triglyceride content and its relation to body adiposity: a magnetic resonance imaging and proton magnetic resonance spectroscopy study. Gut $\mathbf{5 4}, 122-127$.

46. Szczepaniak LS, Nurenberg P, Leonard D, et al. (2005) Magnetic resonance spectroscopy to measure hepatic triglyceride content: prevalence of hepatic steatosis in the general population. Am J Physiol Endocrinol Metab 288, E462-E468.

47. Hamilton G, Yokoo T, Bydder M, et al. (2010) In vivo characterization of the liver fat (1)H MR spectrum. NMR Biomed 24, 784-790.

48. Machann J, Thamer C, Schnoedt B, et al. (2006) Hepatic lipid accumulation in healthy subjects: a comparative study using spectral fat-selective MRI and volume-localized ${ }^{1}$ H-MR spectroscopy. Magn Reson Med 55, 913-917.

49. Tarasów E, Siergiejczyk L, Panasiuk A, et al. (2002) MR proton spectroscopy in liver examinations of healthy individuals in vivo. Med Sci Monit 8, MT36-MT40.

50. Thomas EL \& Bell JD (2006) Intra-cellular fat accumulation, mechanisms and implications for health. Int J Body Comp Res 4, 39-43.

51. Lingvay I, Esser V, Legendre JL, et al. (2009) Non-invasive quantification of pancreatic fat in humans. J Clin Endocrinol Metab 94, 4070-4076.

52. Szczepaniak LS, Dobbins RL \& Metzger GJ (2003) Myocardial triglycerides and systolic function in humans: in vivo evaluation by localized proton spectroscopy and cardiac imaging. Magn Reson Med 49, 417-423.

53. Demerath EW, Reed D, Rogers N, et al. (2008) Visceral adiposity and its anatomical distribution as predictors of the metabolic syndrome and cardiometabolic risk factor levels. Am J Clin Nutr 88, 1263-1271.

54. Fabbrini E, Magkos F, Mohammed BS, et al. (2009) Intrahepatic fat, not visceral fat, is linked with metabolic complications of obesity. Proc Natl Acad Sci U S A 106, $15430-15435$.

55. Hwang JH, Stein DT, Barzilai N, et al. (2007) Increased intrahepatic triglyceride is associated with peripheral insulin resistance: in vivo MR imaging and spectroscopy studies. Am J Physiol Endocrinol Metab 293, E1663-E1669.

56. Porter SA, Massaro JM, Hoffmann U, et al. (2009) Abdominal subcutaneous adipose tissue: a protective fat depot? Diabetes Care 32, 1068-1075.

57. Montague CT, Prins JB, Sanders L, et al. (1997) Depot- and sex-specific differences in human leptin mRNA expression: implications for the control of regional fat distribution. Diabetes $\mathbf{4 6}, 342-347$.

58. Goldstone AP, Brynes AE, Thomas EL, et al. (2002) Resting metabolic rate, plasma leptin concentrations, leptin receptor expression, and adipose tissue measured by whole-body magnetic resonance imaging in women with Prader-Willi syndrome. Am J Clin Nutr 75, 468-475.
59. Magni P, Liuzzi A, Ruscica M, et al. (2005) Free and bound plasma leptin in normal weight and obese men and women: relationship with body composition, resting energy expenditure, insulin-sensitivity, lipid profile and macronutrient preference. Clin Endocrinol 62, 189-196.

60. Forouhi NG, Jenkinson G, Thomas EL, et al. (1999) Relation of triglyceride stores in skeletal muscle cells to central obesity and insulin sensitivity in European and South Asian men. Diabetologia 42, 932-935.

61. Sinha R, Dufour S, Petersen KF, et al. (2002) Assessment of skeletal muscle triglyceride content by (1)H nuclear magnetic resonance spectroscopy in lean and obese adolescents: relationships to insulin sensitivity, total body fat, and central adiposity. Diabetes 51, 1022-1027.

62. Gan SK, Kriketos AD, Poynten AM, et al. (2003) Insulin action, regional fat, and myocyte lipid: altered relationships with increased adiposity. Obes Res 11, 1295-1305.

63. Thomas EL, Frost G, Barnard ML, et al. (1996) An in vivo ${ }^{13} \mathrm{C}$ magnetic resonance spectroscopic study of the relationship between diet and adipose tissue composition. Lipids 31, 145-151.

64. Hwang JH, Bluml S, Leaf A, et al. (2003) In vivo characterization of fatty acids in human adipose tissue using natural abundance ${ }^{1} \mathrm{H}$ decoupled ${ }^{13} \mathrm{C}$ MRS at $1.5 \mathrm{~T}$ : clinical applications to dietary therapy. NMR Biomed $\mathbf{1 6}$ $160-167$.

65. Jones A Jr, Shen W, St-Onge MP, et al. (2004) Body-composition differences between African American and white women: relation to resting energy requirements. $\mathrm{Am} \mathrm{J}$ Clin Nutr 79, 780-786.

66. Liska D, Dufour S, Zern TL, et al. (2007) Interethnic differences in muscle, liver and abdominal fat partitioning in obese adolescents. PLoS One 2, e569.

67. Lê KA, Ventura EE, Fisher JQ, et al. (2011) Ethnic differences in pancreatic fat accumulation and its relationship with other fat depots and inflammatory markers. Diabetes Care 34, 485-490.

68. Harrington TA, Thomas EL, Frost G, et al. (2004) Distribution of adipose tissue in the newborn. Pediatr Res 55, 437-441.

69. Modi N, Thomas EL, Harrington TA, et al. (2006) Determinants of adiposity during preweaning postnatal growth in appropriately grown and growth-restricted term infants. Pediatr Res 60, 345-348.

70. Kuk JL \& Ross R (2009) Influence of sex on total and regional fat loss in overweight and obese men and women. Int J Obes 33, 629-634.

71. Rankinen T, Zuberi A, Chagnon YC, et al. (2006) The human obesity gene map: the 2005 update. Obesity 14, 529-644.

72. Kilpeläinen TO, Zillikens MC, Stančákova A, et al. (2011) Genetic variation near IRS1 associates with reduced adiposity and an impaired metabolic profile. Nat Genet $\mathbf{4 3}$ 753-760.

73. Speliotes EK, Willer CJ, Berndt SI, et al. (2010) Association analyses of 249,796 individuals reveal 18 new loci associated with body mass index. Nat Genet 42, 937-948.

74. Lindgren CM, Heid IM, Randall JC, et al. (2009) Genomewide association scan meta-analysis identifies three loci influencing adiposity and fat distribution. PLoS Genet 5, e1000508.

75. Heid IM, Jackson AU, Randall JC, et al. (2010) Meta-analysis identifies 13 new loci associated with waist-hip ratio and reveals sexual dimorphism in the genetic basis of fat distribution. Nat Genet 42, 949-960.

76. Speliotes EK, Massaro JM, Hoffmann U, et al. (2010) Fatty liver is associated with dyslipidemia and dysglycemia 
independent of visceral fat: the Framingham Heart Study. Hepatology 51, 1979-1987.

77. Must A, Spadano J, Coakley EH, et al. (1999) The disease burden associated with overweight and obesity. JAMA 282, 1523-1529.

78. Després JP, Lemieux I, Bergeron J, et al. (2008) Abdominal obesity and the metabolic syndrome: contribution to global cardiometabolic risk. Arterioscler Thromb Vasc Biol 28, 1039-1049.

79. Kuk JL, Katzmarzyk PT, Nichaman MZ, et al. (2006) Visceral fat is an independent predictor of all-cause mortality in men. Obesity 14, 336-341.

80. Stefan N, Kantartzis K, Machann J, et al. (2008) Identification and characterization of metabolically benign obesity in humans. Arch Intern Med 168, 1609-1616.

81. Wildman RP, Muntner P, Reynolds K, et al. (2008) The obese without cardiometabolic risk factor clustering and the normal weight with cardiometabolic risk factor clustering: prevalence and correlates of 2 phenotypes among the US population (NHANES 1999-2004). Arch Intern Med 168, 1617-1624.

82. McAuley PA \& Blair SN (2011) Obesity paradoxes. J Sports Sci 29, 773-782.

83. Pataky Z, Makoundou V \& Nilsson P (2011) Metabolic normality in overweight and obese subjects. Which parameters? Which risks? Int J Obes 35, 1208-1215.

84. Karelis AD, St-Pierre DH, Conus F, et al. (2004) Metabolic and body composition factors in subgroups of obesity: what do we know? J Clin Endocrinol Metab 89, $2569-2575$.

85. Ferrannini E, Natali A, Bell P, et al. (1997) Insulin resistance and hypersecretion in obesity. European Group for the Study of Insulin Resistance (EGIR). J Clin Invest 100, $1166-1173$.

86. Bonora E, Kiechl S, Willeit J, et al. (1998) Prevalence of insulin resistance in metabolic disorders: the Bruneck Study. Diabetes 47, 1643-1649.

87. Wildman RP (2009) Healthy obesity. Curr Opin Clin Nutr Metab Care 12, 438-443.

88. Lee CD, Blair SN \& Jackson AS (1999) Cardiorespiratory fitness, body composition, and all-cause and cardiovascular disease mortality in men. Am J Clin Nutr 69, 373-380.

89. Wei M, Kampert JB, Barlow CE, et al. (1999) Relationship between low cardiorespiratory fitness and mortality in normal-weight, overweight, and obese men. JAMA 282, $1547-1553$.

90. O'Donovan G, Thomas EL, McCarthy JP, et al. (2009) Fat distribution in men of different waist girth, fitness level and exercise habit. Int J Obes 33, 1356-1362.

91. Björntorp P (1991) Metabolic implications of body fat distribution. Diabetes Care 14, 1132-1143.

92. Brochu M, Tchernof A, Dionne IJ, et al. (2001) What are the physical characteristics associated with a normal metabolic profile despite a high level of obesity in postmenopausal women? J Clin Endocrinol Metab 86, 1020-1025.

93. Matsuzawa Y (1997) Pathophysiology and molecular mechanisms of visceral fat syndrome: the Japanese experience. Diabetes Metab Rev 13, 3-13.

94. Matsuzawa Y, Fujioka S, Tokunaga K, et al. (1992) Classification of obesity with respect to morbidity. Proc Soc Exp Biol Med 200, 197-201.

95. Lee DC, Sui X \& Blair SN (2009) Does physical activity ameliorate the health hazards of obesity? Br J Sports Med 43, 49-51.

96. Ruderman NB, Schneider SH \& Berchtold P (1981) The "metabolically-obese," normal-weight individual. Am J Clin Nutr 34, 1617-1621.
97. Conus F, Rabasa-Lhoret R \& Péronnet F (2007) Characteristics of metabolically obese normal-weight (MONW) subjects. Appl Physiol Nutr Metab 32, 4-12.

98. De Lorenzo A, Martinoli R, Vaia F, et al. (2006) Normal weight obese (NWO) women: an evaluation of a candidate new syndrome. Nutr Metab Cardiovasc Dis 16, $513-523$.

99. Conus F, Allison DB, Rabasa-Lhoret R, et al. (2004) Metabolic and behavioral characteristics of metabolically obese but normal-weight women. J Clin Endocrinol Metab 89, 5013-5020.

100. St-Onge MP, Janssen I \& Heymsfield SB (2004) Metabolic syndrome in normal-weight Americans: new definition of the metabolically obese, normal-weight individual. Diabetes Care 27, 2222-2228.

101. Katsuki A, Sumida Y, Urakawa H, et al. (2003) Increased visceral fat and serum levels of triglyceride are associated with insulin resistance in Japanese metabolically obese, normal weight subjects with normal glucose tolerance. Diabetes Care 26, 2341-2344.

102. Dvorak RV, DeNino WF, Ades PA, et al. (1999) Phenotypic characteristics associated with insulin resistance in metabolically obese but normal-weight young women. Diabetes 48, 2210-2214

103. Ruderman N, Chisholm D, Pi-Sunyer X, et al. (1998) The metabolically obese, normal-weight individual revisited. Diabetes 47, 699-713.

104. Matsuzawa Y, Nakamura T, Shimomura I, et al. (1995) Visceral fat accumulation and cardiovascular disease. Obes Res 3, Suppl. 5, 645S-647S.

105. Després JP \& Lemieux I (2006) Abdominal obesity and metabolic syndrome. Nature 444, 881-887.

106. Unger RH, Zhou YT \& Orci L (1999) Regulation of fatty acid homeostasis in cells: novel role of leptin. Proc Natl Acad Sci US A 96, 2327-2332.

107. Unger RH (1995) Lipotoxicity in the pathogenesis of obesity dependent NIDDM. Genetic and clinical implications. Diabetes 44, 863-870.

108. Unger RH (2003) Minireview: weapons of lean body mass destruction: the role of ectopic lipids in the metabolic syndrome. Endocrinology 144, 5159-5165.

109. Montani JP, Carroll JF, Dwyer TM, et al. (2004) Ectopic fat storage in heart, blood vessels and kidneys in the pathogenesis of cardiovascular diseases. Int J Obes Relat Metab Disord 28, S58-S65.

110. Petersen KF, Oral EA, Dufour S, et al. (2002) Leptin reverses insulin resistance and hepatic steatosis in patients with severe lipodystrophy. J Clin Invest 109, 1345-1350.

111. Hegele RA, Joy TR, Al-Attar SA, et al. (2007) Thematic review series: Adipocyte biology. Lipodystrophies: windows on adipose biology and metabolism. J Lipid Res $\mathbf{4 8}$, 1433-1444.

112. Stearns SB, Tepperman HM \& Tepperman J (1979) Studies on the utilization and mobilization of lipid in skeletal muscles from streptozotocin-diabetic and control rats. J Lipid Res 20, 654-662.

113. Standl E, Lotz N, Dexel T, et al. (1980) Muscle triglycerides in diabetic subjects. Effect of insulin deficiency and exercise. Diabetologia 18, 463-469.

114. Falholt K, Jensen I, Lindkaer Jensen S, et al. (1988) Carbohydrate and lipid metabolism of skeletal muscle in type 2 diabetic patients. Diabet Med 5, 27-31.

115. Storlien LH, Jenkins AB, Chisholm DJ, et al. (1991) Influence of dietary fat composition on development of insulin resistance in rats. Relationship to muscle triglyceride and omega-3 fatty acids in muscle phospholipid. Diabetes $\mathbf{4 0}$, 280-289. 
116. Kraegen EW, Clark PW, Jenkins AB, et al. (1991) Development of muscle insulin resistance after liver insulin resistance in high fat-fed rats. Diabetes 40, 1397-1403.

117. Phillips DI, Caddy S, Ilic V, et al. (1996) Intramuscular triglyceride and muscle insulin sensitivity: evidence for a relationship in non diabetic subjects. Metabolism 45, 947-950.

118. Pan DA, Lillioja S, Kriketos AD, et al. (1997) Skeletal muscle triglyceride levels are inversely related to insulin action. Diabetes 46, 983-988.

119. Pepper W (1884) Saccharine diabetes. Med Rec 25, 9-12.

120. Zelman S (1952) The liver in obesity. Arch Int Med 90 , $141-156$.

121. Connor CL (1938) Fatty infiltration of the liver and the development of cirrhosis in diabetes and chronic alcoholism. Am J Pathol 14, 347-364.

122. Leevy CM, Ryan CM \& Fineberg JC (1950) Diabetes mellitus and liver dysfunction - etiological and therapeutic considerations. Am J Med 8, 290-299.

123. Kern WH, Heger AH \& Payne JH (1973) Fatty metamorphosis of the liver in morbid obesity. Arch Pathol 96, 342-346.

124. Ekstedt M, Franzén LE, Mathiesen UL, et al. (2006) Longterm follow-up of patients with NAFLD and elevated liver enzymes. Hepatology 44, 865-873.

125. Adams LA, Waters OR, Knuiman MW, et al. (2009) NAFLD as a risk factor for the development of diabetes and the metabolic syndrome: an eleven-year follow-up study. Am J Gastroenterol 104, 861-867.

126. Powell EE, Cooksley WG, Hanson R, et al. (1990) The natural history of non-alcoholic steatohepatitis: a follow-up study of forty-two patients for up to 21 years. Hepatology 11, 74-80.

127. Vernon G, Baranova A \& Younossi ZM (2011) Systematic review: the epidemiology and natural history of nonalcoholic fatty liver disease and non-alcoholic steatohepatitis in adults. Aliment Pharmacol Ther 34, 274-285.

128. Bays H, Mandarino L \& DeFronzo RA (2004) Role of the adipocyte, free fatty acids, and ectopic fat in pathogenesis of type 2 diabetes mellitus: peroxisomal proliferator-activated receptor agonists provide a rational therapeutic approach. J Clin Endocrinol Metab 89, 463-478.

129. Lelliott C \& Vidal-Puig AJ (2004) Lipotoxicity, an imbalance between lipogenesis de novo and fatty acid oxidation. Int J Obes Relat Metab Disord 28, Suppl. 4, S22-S28.

130. Dasarathy S, Dasarathy J, Khiyami A, et al. (2009) Validity of real time ultrasound in the diagnosis of hepatic steatosis: a prospective study. J Hepatol 51, 1061-1067.

131. Magkos F, Fabbrini E, Mohammed BS, et al. (2010) Increased whole-body adiposity without a concomitant increase in liver fat is not associated with augmented metabolic dysfunction. Obesity 18, 1510-1515.

132. Yim JE, Heshka S, Albu J, et al. (2007) Intermuscular adipose tissue rivals visceral adipose tissue in independent associations with cardiovascular risk. Int $J$ Obes 31, $1400-1405$.

133. Goodpaster BH, Thaete FL, Simoneau JA, et al. (1997) Subcutaneous abdominal fat and thigh muscle composition predict insulin sensitivity independently of visceral fat. Diabetes 46, 1579-1585.
134. Thomas EL, Brynes AE, McCarthy J, et al. (2000) Preferential loss of visceral fat following aerobic exercise, measured by magnetic resonance imaging. Lipids 35, 769-776.

135. Idoate F, Ibañez J, Gorostiaga EM, et al. (2011) Weight-loss diet alone or combined with resistance training induces different regional visceral fat changes in obese women. Int J Obes 35, 700-713.

136. van der Heijden GJ, Wang ZJ, Chu ZD, et al. (2010) A 12-week aerobic exercise program reduces hepatic fat accumulation and insulin resistance in obese, Hispanic adolescents. Obesity 18, 384-390.

137. Johnson NA, Sachinwalla T, Walton DW, et al. (2009) Aerobic exercise training reduces hepatic and visceral lipids in obese individuals without weight loss. Hepatology 50, 1105-1112.

138. Ross R, Janssen I, Dawson J, et al. (2004) Exercise-induced reduction in obesity and insulin resistance in women: a randomized controlled trial. Obes Res 12, 789-798.

139. Larson-Meyer DE, Heilbronn LK, Redman LM, et al. (2006) Effect of calorie restriction with or without exercise on insulin sensitivity, $\beta$-cell function, fat cell size, and ectopic lipid in overweight subjects. Diabetes Care 29, 1337-1344.

140. Thomas EL, Brynes AE, Hamilton G, et al. (2006) Effect of nutritional counselling on hepatic, muscle and adipose tissue fat content and distribution in non-alcoholic fatty liver disease. World J Gastroenterol 12, 5813-5819.

141. Gasteyger C, Larsen TM, Vercruysse F, et al. (2009) Visceral fat loss induced by a low-calorie diet: a direct comparison between women and men. Diabetes Obes Metab 11, 596-602.

142. Janssen I, Fortier A, Hudson R, et al. (2002) Effects of an energy-restrictive diet with or without exercise on abdominal fat, intermuscular fat, and metabolic risk factors in obese women. Diabetes Care 25, 431-438.

143. Doucet E, St-Pierre S, Alméras N, et al. (2002) Reduction of visceral adipose tissue during weight loss. Eur J Clin Nutr 56, 297-304.

144. Leenen R, van der Kooy K, Droop A, et al. (1993) Visceral fat loss measured by magnetic resonance imaging in relation to changes in serum lipid levels of obese men and women. Arterioscler Thromb 13, 487-494.

145. Montgomery HE, Marshall R, Hemingway H, et al. (1998) Human gene for physical performance. Nature 393, 221-222.

146. Rankinen T, Roth SM, Bray MS, et al. (2010) Advances in exercise, fitness, and performance genomics. Med Sci Sports Exerc 42, 835-846.

147. Bouchard C (2008) Gene-environment interactions in the etiology of obesity: defining the fundamentals. Obesity $\mathbf{3}$, Suppl., S5-S10.

148. Hannukainen JC, Borra R, Linderborg K, et al. (2011) Liver and pancreatic fat content and metabolism in healthy monozygotic twins with discordant physical activity. $J$ Hepatol 54, 545-552.

149. Mustelin L, Pietiläinen KH \& Rissanen A (2008) Acquired obesity and poor physical fitness impair expression of genes of mitochondrial oxidative phosphorylation in monozygotic twins discordant for obesity. Am J Physiol Endocrinol Metab 295, E148-E154. 